\title{
Dimension Analysis-Based Model for Prediction of Shale Compressive Strength
}

\author{
Xiangyu Fan, ${ }^{1}$ Fenglin Xu, ${ }^{1,2}$ Lin Chen, ${ }^{3}$ Qiao Chen, ${ }^{1,2}$ Zhiwei Liu, ${ }^{1}$ \\ Guanghua Yao, ${ }^{4}$ and Wen $\mathrm{Nie}^{1}$ \\ ${ }^{1}$ School of Petroleum and Natural Gas Engineering, Southwest Petroleum University, Chengdu 610500, China \\ ${ }^{2}$ Chongqing Institute of Green and Intelligent Technology, Chinese Academy of Sciences, Chongqing 400714, China \\ ${ }^{3}$ School of Sciences, Southwest Petroleum University, Chengdu 610500, China \\ ${ }^{4}$ Chongqing Mineral Resources Development Co., Ltd., Chongqing 40042, China
}

Correspondence should be addressed to Wen Nie; niewen1026@gmail.com

Received 17 January 2016; Accepted 22 May 2016

Academic Editor: Fernando Lusquiños

Copyright (C) 2016 Xiangyu Fan et al. This is an open access article distributed under the Creative Commons Attribution License, which permits unrestricted use, distribution, and reproduction in any medium, provided the original work is properly cited.

\begin{abstract}
The compressive strength of shale is a comprehensive index for evaluating the shale strength, which is linked to shale well borehole stability. Based on correlation analysis between factors (confining stress, height/diameter ratio, bedding angle, and porosity) and shale compressive strength (Longmaxi Shale in Sichuan Basin, China), we develop a dimension analysis-based model for prediction of shale compressive strength. A nonlinear-regression model is used for comparison. A multitraining method is used to achieve reliability of model prediction. The results show that, compared to a multi-nonlinear-regression model (average prediction error $=19.5 \%$ ), the average prediction error of the dimension analysis-based model is $19.2 \%$. More importantly, our dimension analysisbased model needs to determine only one parameter, whereas the multi-nonlinear-regression model needs to determine five. In addition, sensitivity analysis shows that height/diameter ratio has greater sensitivity to compressive strength than other factors.
\end{abstract}

\section{Introduction}

Shale compressive strength is an important parameter that reflects the shale brittleness, and thus it is used as a comprehensive index to evaluate the stability of shale well boreholes. Most shale types have flaky bedding which is obviously anisotropic, which affects the performance of the rock strength. Thus, the physical properties of shale strongly affect the shale compressive strength. A common way to evaluate the effect of rock properties on rock strength is to carry out triaxial compressive experiments in the laboratory and then to analyze the relation between factors and rock strength. Knowledge of the shale anisotropy is vital for borehole instability issues [1,2]. A total of three triaxial tests with different sample orientations (i.e., 0, 45, 60, and $90^{\circ}$ ), including Brazilian tests and CT scans, were used to investigate how the bedding angle affects the shale strength [3]. In particular, Lyu et al. [4] present an experimental study of the effects of bedding planes on the mechanical properties of Chinese shale samples (Sichuan Basin, China). Hudson et al. [5] carried out uniaxial compression tests of marbles of different sizes to obtain the rock strength with the aspect to the height/diameter ratio. It was found that an increase of the height/diameter ratio reduced the rock strength until it reached a relatively stable value. Hoek [6] suggests that this reduction in strength is due to the increased probability that failure of rock grains will occur as the specimen size increases. Pells [7] found that $150 \mathrm{~mm}$ specimens have strength of around $85 \%$ of that of $50 \mathrm{~mm}$ specimens. Darlington et al. [8] found that the multifractal scaling law (MFSL) model most closely predicts the strengthsize relationship in rock and cementitious materials. $\mathrm{Li}$ and Aubertin [9] showed that increases in porosity within the rock reduce the compressive, tensile, and shear strengths of the intact rock. Similar results were also obtained by Chang et al. [10], Horsrud [11], and Lashkaripour and Dusseault [12]. It is comprehensively accepted that an increase of the confining stress improves the rock compressive strength; for example, 

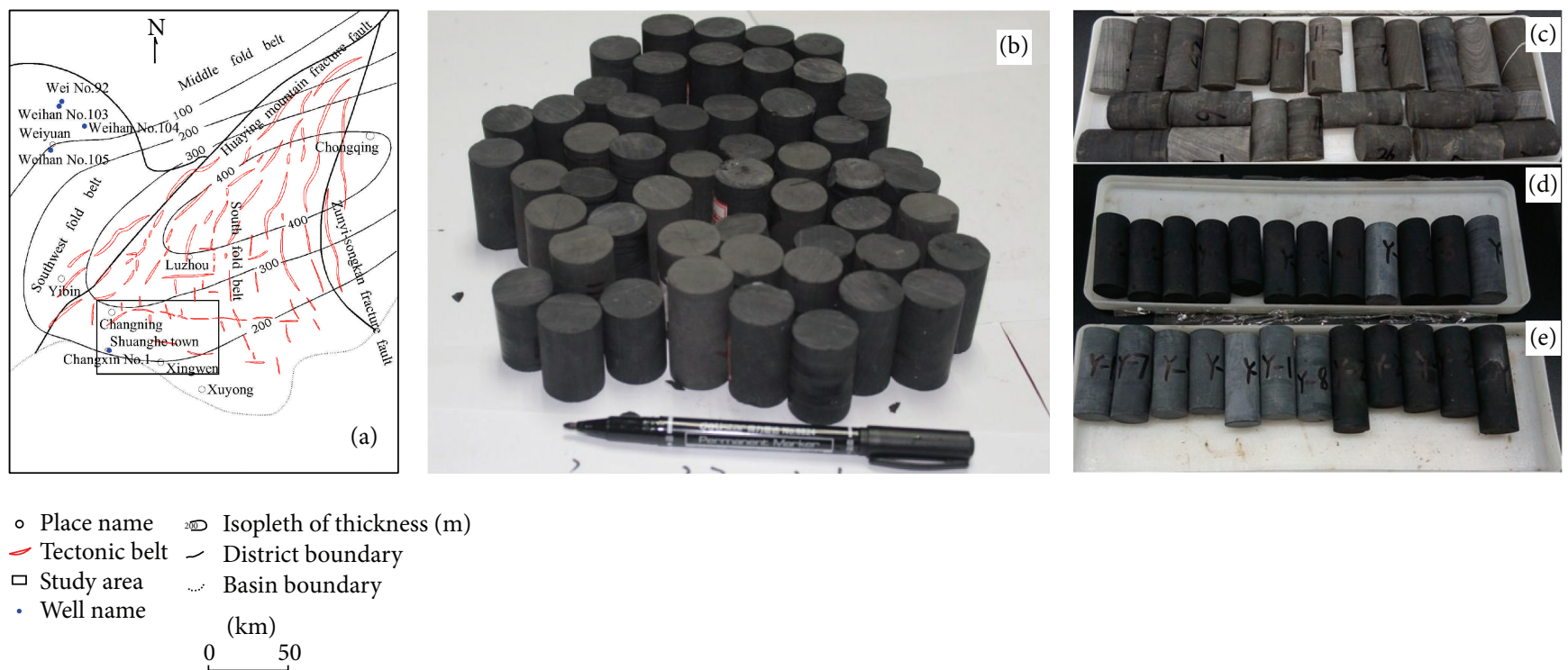

FIGURE 1: Information on shale specimen: (a) tectonic map, (b) shale specimen, (c) specimens with different bedding angles, (d) specimens with different porosities, and (e) specimens with different ratios of height/diameter ratio.

Liang et al. [13] found that the elastic modulus of bedded salt rock increases with an increase in the confining stress. Lal [14] focused especially on the similar relation between confining stress and compressive strength. In summary, it is considered that the main factors of porosity, geometry, bedding angle, and confining stress affect the shale compressive strength. Therefore, considering the effect of only one factor on the shale strength may not reflect the true shale strength. Currently, rock strength prediction mainly depends on a multi-nonlinear-regression model $[15,16]$. This type of method requires the determination of many parameters and has less physical meaning. In our study, we consider the shale specimens from the Longmaxi Shale in Sichuan Basin, China, by carrying out a correlation analysis between the main factors (confining stress, height/diameter ratio, bedding angle, and porosity) and the shale compressive strength. A dimension analysis-based model is developed to predict the shale compressive strength. A multi-nonlinear-regression model based on the same data is used for comparison.

\section{Shale Specimen and Experiments}

2.1. Introduction of Shale Origin and Shale Specimens. The Sichuan Basin is a prolific hydrocarbon region and is currently China's largest gas-producing region. The Longmaxi region in this study is located at the margin of the southern Sichuan Basin. The Sichuan Basin, located in the west of the Yangtze metaplatform tectonically, is large and tectonically stable. The strata are of the South China type, with a complete regional sedimentary rock exposed from a Presinian system to a Quaternary system, whose sedimentary cover thickness is approximately 6000 to $12,000 \mathrm{~m}$ from the Paleozoic to Cenozoic. The Longmaxi Formation (shale) distribution is determined based on the depositional environment and the subsequent erosional events related to the tectonic history. The Longmaxi black shale is the most organically rich part of the Lower Silurian. The Longmaxi Formation has a thickness ranging from 229.2 to $672.5 \mathrm{~m}$. The stratigraphy consists of black shale, black and dark/grey shale, dark grey shale, and silty mudstone, mainly comprising carbonaceous and clay shale. Shale samples are from the "Longmaxi Shale" in Sichuan Basin, China (Figure 1(a)). There are 93 shale specimens. All of the shale specimens have a diameter of $25 \mathrm{~mm}$ and a height between 34.5 and $54 \mathrm{~mm}$. The bedding angles considered are $0,15,30,45,60,75$, and $90^{\circ}$, respectively. The range of porosity is from 1.7 to $5.4 \%$ (Figures $1(\mathrm{~b})-1(\mathrm{e})$ ). The shale samples generally belong to black shale, also called carboniferous shale. The variety of shale contains abundant organic matter, pyrite, and sometimes carbonate nodules or layers as well as, in some locations, concentrations of copper, nickel, uranium, and vanadium. Black shale is of interest commercially since it is a potentially valuable source of synthetic crude oil and plays an important role in oil-shale formation. In this study, X-ray diffraction (XRD) analysis was used to analyze the mineral components of shale (a total of 20 samples). The relative contents of minerals in the composition and the clay mineral content are shown in Figure 2. A comparison of the mineral compositions of the "Longmaxi" and "North American" shale formations is shown in Figure 3 (the statistical data for Bossier Shale, Ohio Shale, and West Texas Woodford/Barnett are from [17-21]).

2.2. Experimental Devices. We used an RTR-1000 triaxial testing machine (GCTS, USA) for the compressive strength tests. An HK GP-3 type porosity analyzer was used for porosity measurements. An X'Pert Pro powder X-ray diffractometer (from PANalytical) was used for the $\mathrm{XRD}$ analysis.

\section{Correlation Analyses}

The relation between height and diameter (1.62-1.94) and compressive shale strength is shown in Figure 4(a). The 


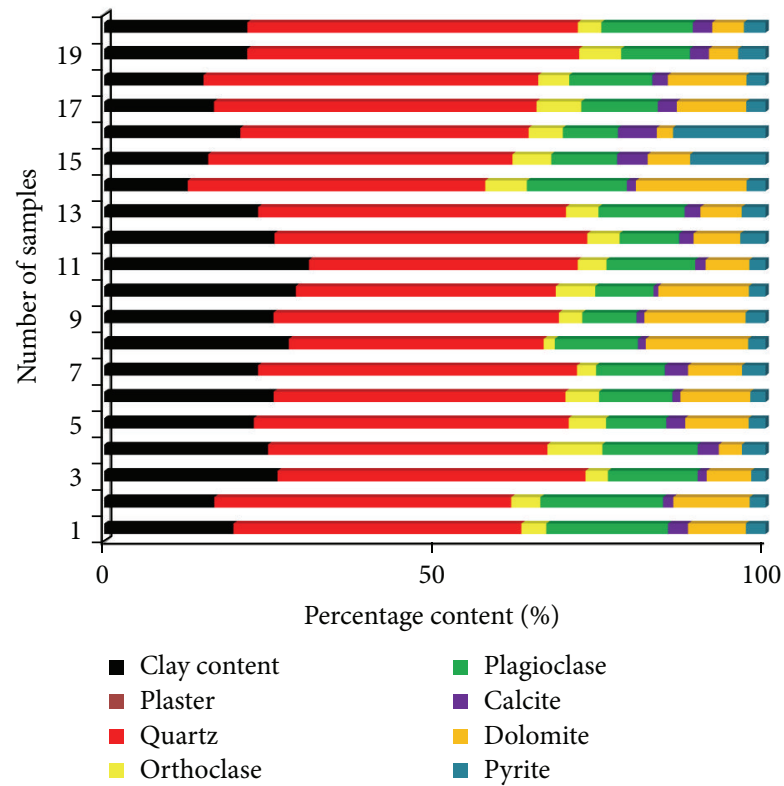

(a)

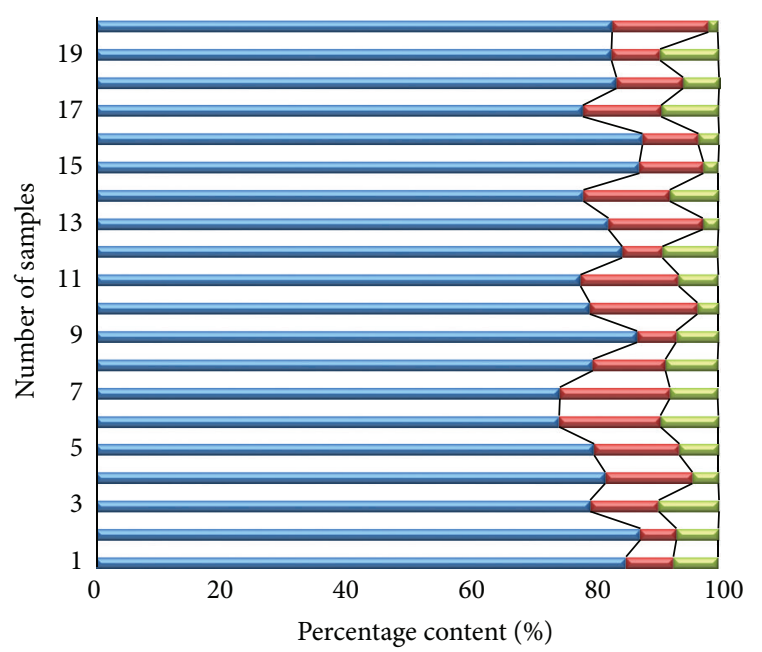

IIlite

a Chlorite

■ Illite mixed montmorillonite

(b)

FIGURE 2: Analysis of mineral composition: (a) the relative contents of minerals in the composition; (b) clay mineral content.

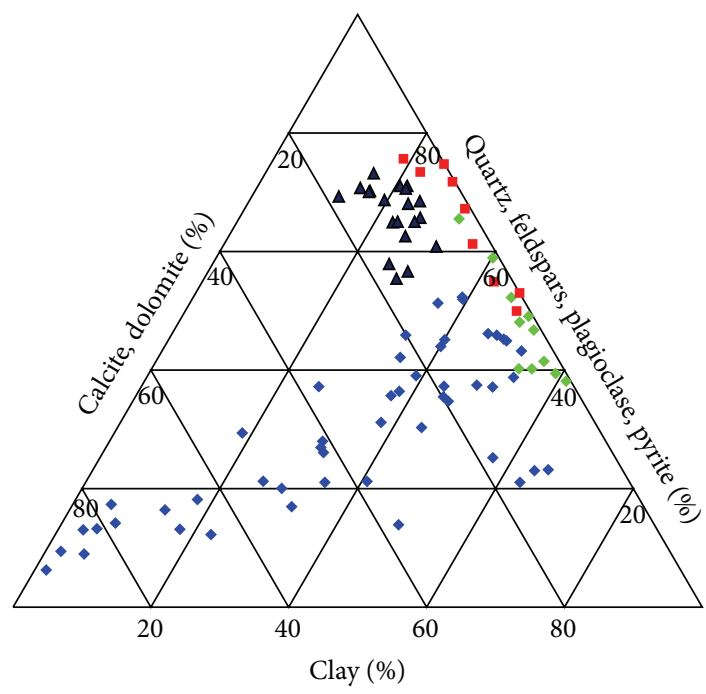

- Bossier Shale

- Ohio Shale

- West Texas Woodford/Barnett

$\Delta$ Longmaxi Formation, Chongqing

FIgURE 3: Comparison of the mineral compositions of shale formations (the statistical data for Bossier Shale, Ohio Shale, and West Texas Woodford/Barnett are taken from [17-21]).

bedding angles of specimens are $30^{\circ}$ and the porosity is $\sim 1.9 \%$. The confining stress is $0 \mathrm{MPa}$. The relation between porosity $(1.7-5.3 \%)$ and compressive shale strength is shown in Figure 4(b). The bedding angle of these specimens is $0^{\circ}$ and the confining stress is $0 \mathrm{MPa}$. The height/diameter ratio is 2 . The relation between confining stress $(0-30 \mathrm{MPa})$ and compressive shale strength is shown in Figure 4(c). The bedding angle of these specimens is $15^{\circ}$ and the porosity is
1.9. The height/diameter ratio is 2 . The relation between confining stress $\left(0-90^{\circ}\right)$ and compressive shale strength is shown in Figure 4(d). The porosity of specimens is $\sim 1.9 \%$ and the confining stress is $13.5 \mathrm{MPa}$. The height/diameter ratio is 2.

\section{Dimension Analysis-Based Model}

4.1. Model Construction. The compressive strength $(R)$, confining stress $(P)$, diameter $(d)$, bedding angle $(D)$, height $(L)$, and porosity $(\phi)$ were employed to construct the compressive strength prediction model. According to the law of dimensional homogeneity, (1) the above factors are denoted as $x_{1}, x_{2}, \ldots, x_{6}$. The basic dimensions are $\left[X_{1}\right],\left[X_{2}\right], \ldots,\left[X_{6}\right]$, and (2) all the factors are transformed using basic dimensions; that is,

$$
\prod_{i=1}^{n} x_{i}^{\alpha_{i}}=\pi
$$

where $\alpha_{i}$ are the objects, $\pi$ is the dimensionless quantity, and $\pi$ can be rewritten using basic dimensions as follows:

$$
\begin{aligned}
& x_{1}=M L^{-1} T^{-2}, \\
& x_{2}=M L^{-1} T^{-2}, \\
& x_{3}=M^{0} L T^{0}, \\
& x_{4}=M^{0} L^{0} T^{0}, \\
& x_{5}=M^{0} L T^{0}, \\
& x_{6}=M^{0} L^{0} T^{0} .
\end{aligned}
$$




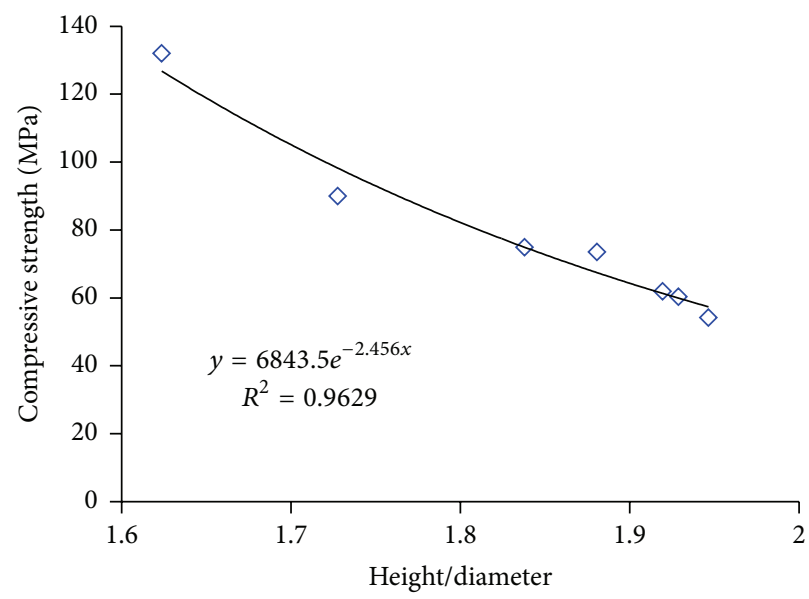

(a)

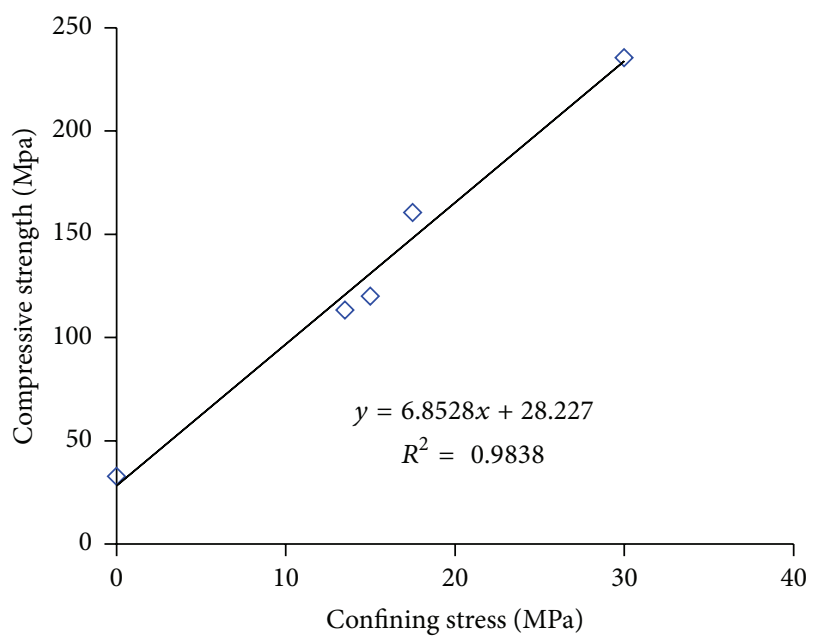

(c)

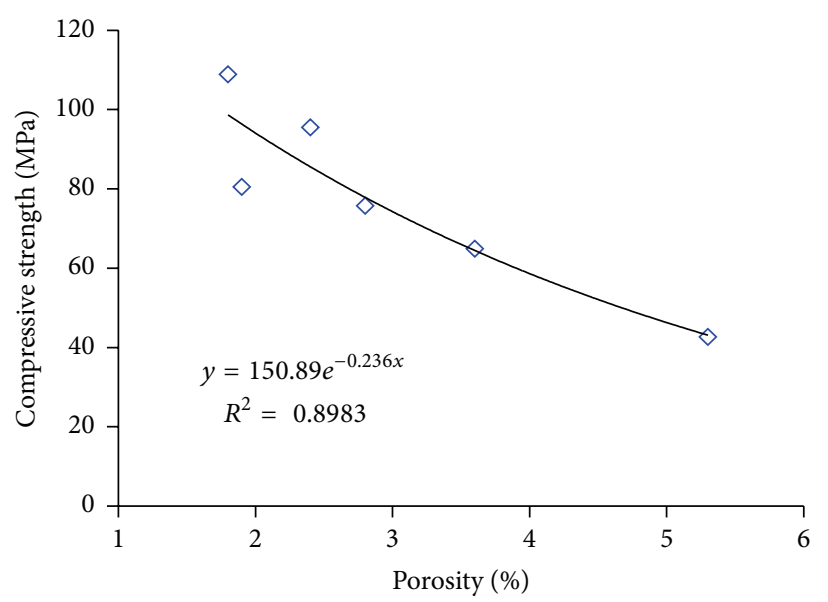

(b)

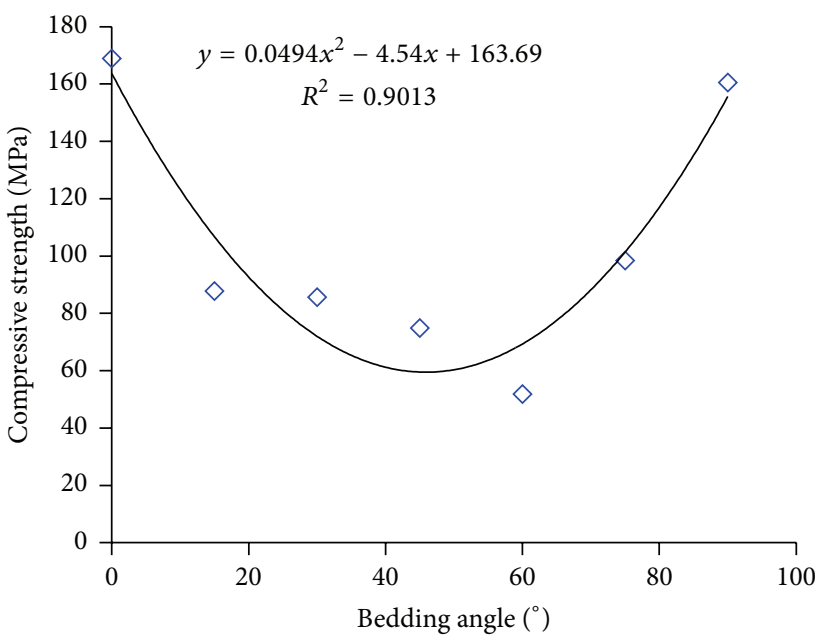

(d)

FIGURE 4: Correlation analysis: (a) height/diameter ratio versus compressive strength; (b) porosity versus compressive strength; (c) confining stress versus compressive strength; (d) bedding angle versus compressive strength.

Substituting (2) into (1), we get

$$
\begin{aligned}
& {\left[M L^{-1} T^{-2}\right]^{\alpha_{1}}\left[M L^{-1} T^{-2}\right]^{\alpha_{2}}\left[M^{0} L T^{0}\right]^{\alpha_{3}}\left[M^{0} L^{0} T^{0}\right]^{\alpha_{4}}} \\
& \cdot\left[M^{0} L T^{0}\right]^{\alpha_{5}}\left[M^{0} L^{0} T^{0}\right]^{\alpha_{6}}=[\pi] .
\end{aligned}
$$

We solve the objects as follows:

$$
\begin{array}{r}
\alpha_{1}+\alpha_{2}=0 \\
-\alpha_{1}-\alpha_{2}+\alpha_{3}+\alpha_{5}=0 \\
-2 \alpha_{1}-2 \alpha_{2}=0 .
\end{array}
$$

The Rank (4) = 2; thus

$$
\vec{\alpha}=\left(\begin{array}{c}
\alpha_{1} \\
\vdots \\
\alpha_{6}
\end{array}\right)
$$

has $n-r=4$ basic answers as follows:

$$
\begin{aligned}
\vec{\alpha}^{(1)} & =\left(\begin{array}{c}
-1 \\
1 \\
1 \\
1 \\
-1 \\
1
\end{array}\right), \\
\vec{\alpha}^{(2)} & =\left(\begin{array}{c}
-1 \\
1 \\
-1 \\
1 \\
1 \\
0
\end{array}\right),
\end{aligned}
$$




$$
\begin{aligned}
\vec{\alpha}^{(3)}= & \left(\begin{array}{c}
-1 \\
1 \\
1 \\
0 \\
-1 \\
1
\end{array}\right), \\
\vec{\alpha}^{(4)}= & \left(\begin{array}{c}
-1 \\
1 \\
-1 \\
0 \\
1 \\
1
\end{array}\right) .
\end{aligned}
$$

The relations among $x_{1}, x_{2}, \ldots, x_{6}$ are as follows:

$$
\begin{aligned}
& \frac{P}{R} \frac{d}{L} \phi \cdot D=\pi_{1}, \\
& \frac{P}{R} \frac{L}{d} D \cdot \phi=\pi_{2}, \\
& \frac{P}{R} \frac{d}{L} D \cdot \phi=\pi_{3}, \\
& \frac{P}{R} \frac{L}{d} D \cdot \phi=\pi_{4},
\end{aligned}
$$

where $\pi_{1}, \pi_{2}, \pi_{3}$, and $\pi_{4}$ are dimensionless quantities.

Thus the final expression is as follows:

$$
R=P \cdot D \cdot \phi \frac{d}{L}
$$

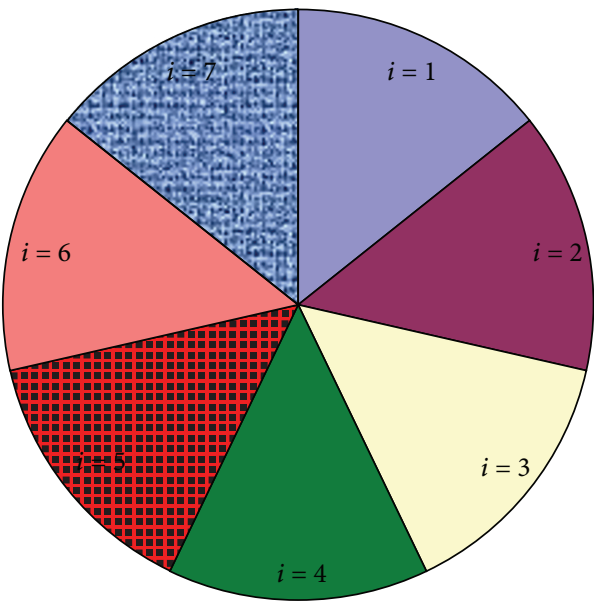

FIGURE 5: Working principle of multitraining and prediction $(i=1$ means that the first six datasets were used for prediction validation, and the rest of the data were used as the training model; $i=2$ means that the second six datasets were used for prediction validation, and the rest of the data were used as the training model; ...,i=6 means that the last six datasets were used for prediction validation, and the rest of the data were used as the training model).

Considering the correlation analysis before, (8) can be modified to give

$$
R=k \cdot(P+28.2) \cdot \frac{1}{1+\phi} \cdot \frac{d}{L} \cdot\left(1+\frac{1}{e^{|D-50| / 50}}\right),
$$

where $k$ is the coefficient, which can be determined by data training.

4.2. Prediction of Model. We randomly chose 36 groups of data as a database for coefficient training (30 groups of data) and validation of the model (six groups of data). In order to increase the reliability of model prediction, we carry out the multitraining and prediction as shown in Figure 5.

Ordinary Least Squares (see (10)) is used to calculate the coefficient:

$$
\begin{aligned}
x^{*}=\underset{x}{\arg \min } & \left\|R-k(P+28.2) \cdot \frac{1}{1+\phi} \cdot \frac{d}{L} \cdot\left(1+\frac{1}{e^{|D-50| / 50}}\right)\right\|_{F}^{2}, \\
\text { s.t. } & P, \phi, d, L, D>0 .
\end{aligned}
$$

The results of training are as shown in Figure 6. The average fitting error is $18.4 \%$ and $k=13.17$.

Figure 7 shows the seven groups of prediction errors of the model and the average error is $19.2 \%$.

\section{Multi-Nonlinear-Regression Model for Comparison}

5.1. Multi-Nonlinear-Regression Model. The compressive strength $(R)$, confining stress $(P)$, height/diameter ratio $(\lambda)$, bedding angle $(D)$, and porosity $(\phi)$ are employed to construct the multi-nonlinear-regression model for compressive strength prediction as expressed by

$$
\begin{aligned}
R= & b_{0}+b_{1} e^{-2.46 \lambda}+b_{2}^{-0.24 \phi}+b_{3} P \\
& +b_{4}\left(0.05 D^{2}-4.54 D\right),
\end{aligned}
$$

where $b_{0}, \ldots, b_{4}$ are the object coefficients. 

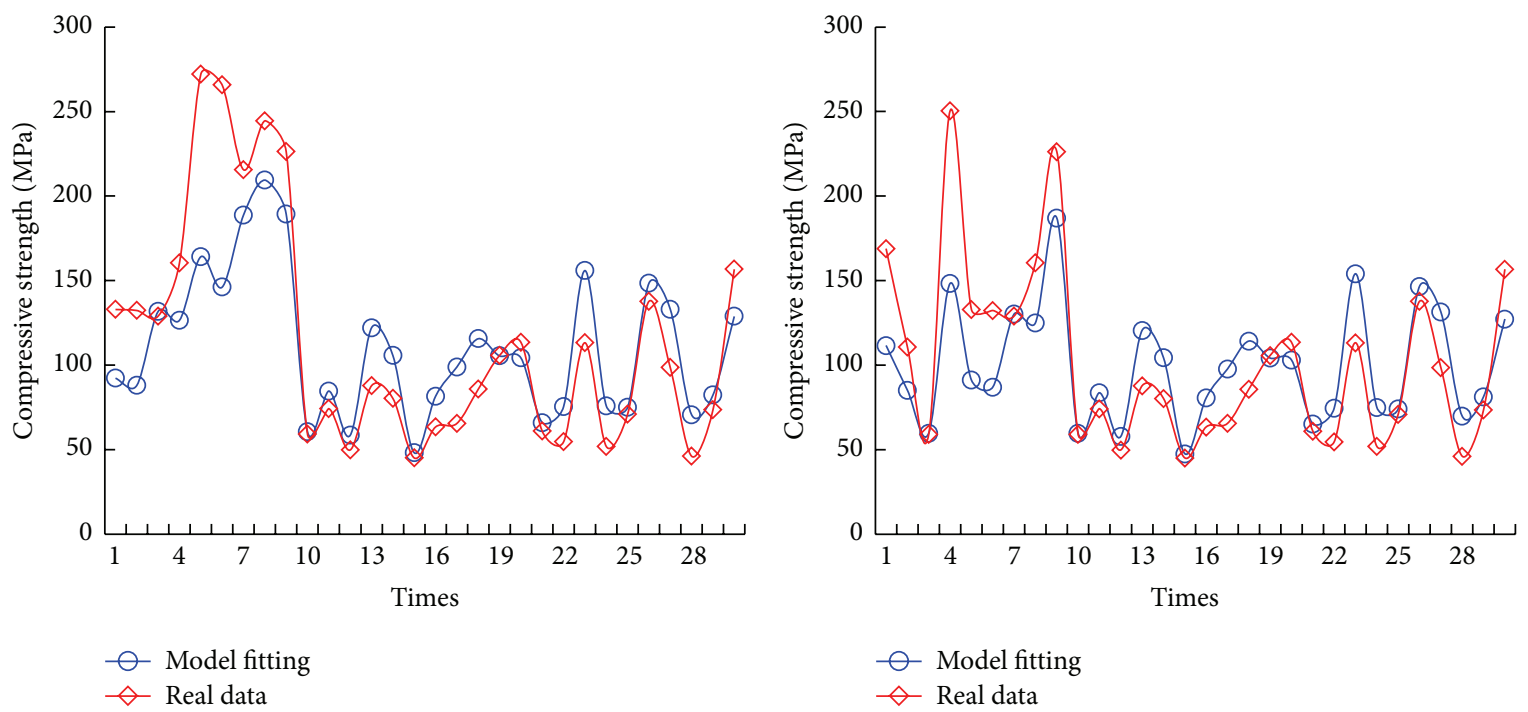

(a)
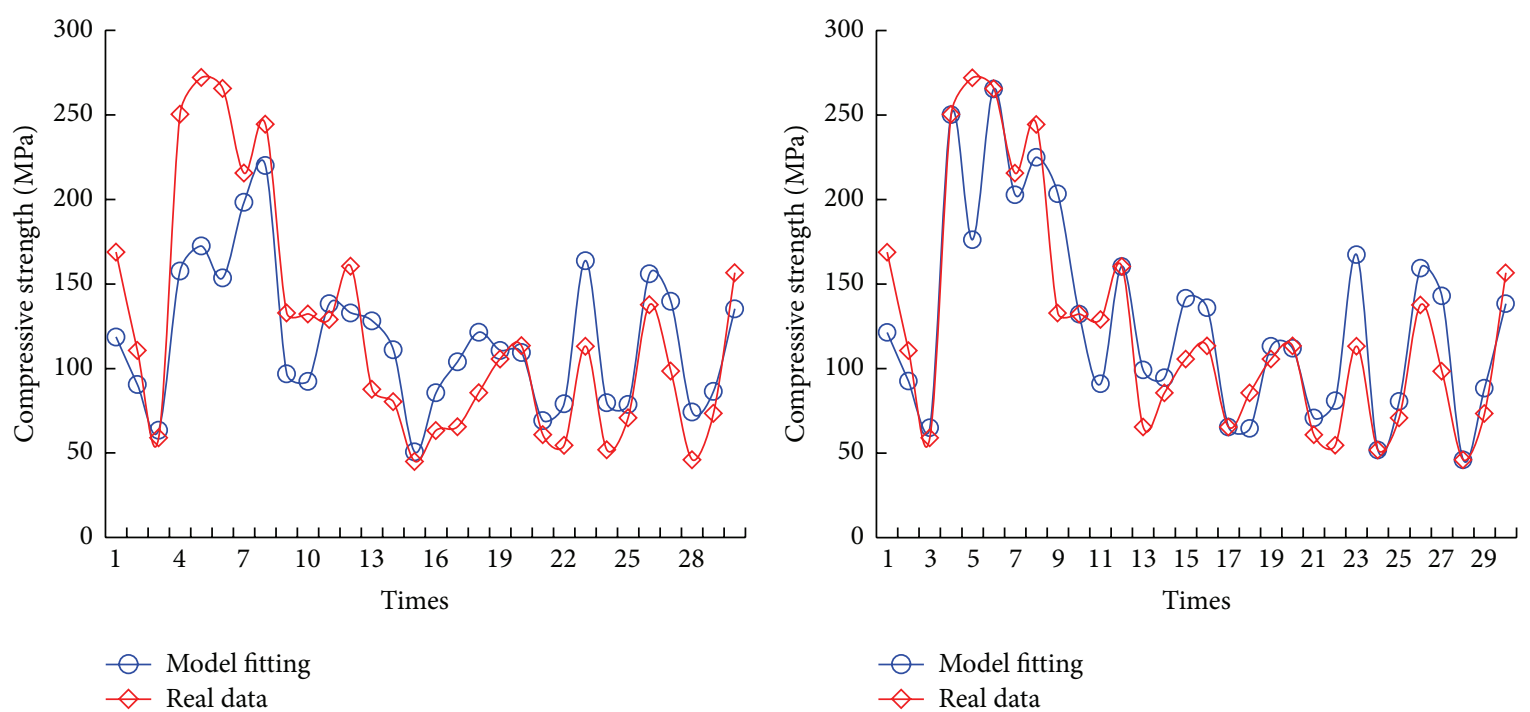

(c)

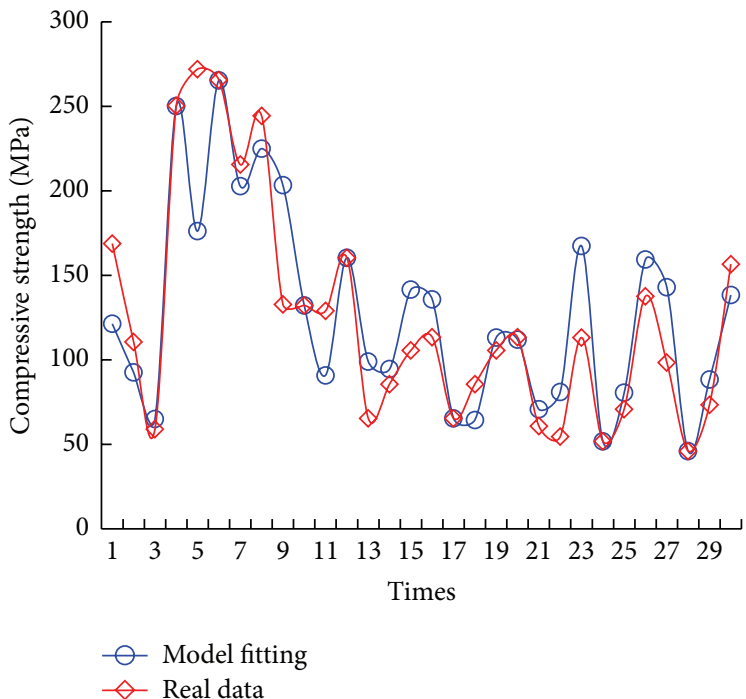

(e)

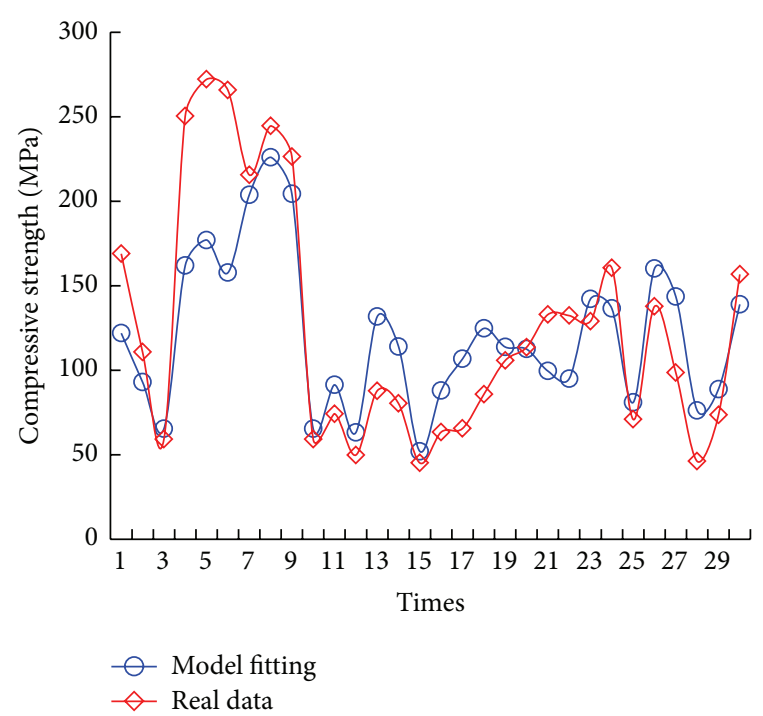

(f)

FIgURE 6: Continued. 


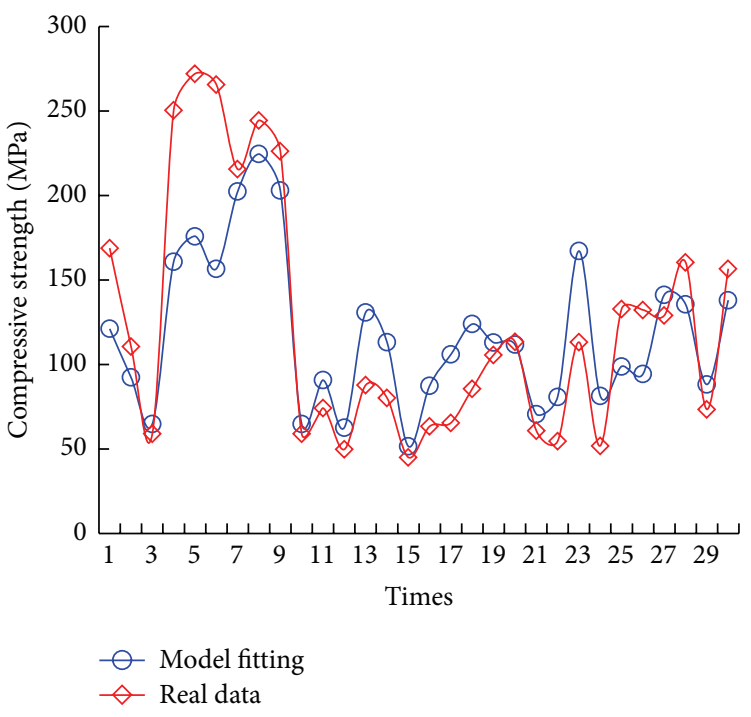

(g)

FIGURE 6: Multitraining results: (a) training on the first group of data; (b) training on the second group of data; (c) training on the third group of data; (d) training on the fourth group of data; (e) training on the fifth group of data; (f) training on the sixth group of data; (g) training on the seventh group of data.

5.2. Prediction of Model. We still use the database for multitraining and prediction as shown in Figure 5. Ordinary Least Squares (see (12)) is used to calculate the coefficients:

$$
\begin{aligned}
& x^{*}=\underset{x}{\arg \min }\left\|R-b_{0}-b_{1} e^{-2.46 \lambda}-b_{2}^{-0.24 \phi}-b_{3} P-b_{4}\left(0.05 D^{2}-4.54 D\right)\right\|_{F}^{2}, \\
& \text { s.t. } \quad P, \phi, \lambda, D>0 \text {. }
\end{aligned}
$$

The results of training are as shown in Figure 8 . The average fitting error is $19.7 \%$ and the values of $b_{0}, \ldots, b_{4}$ are -35.3 , $3254.8,250.9,3.0$, and 0.2 , respectively.

Figure 9 shows the seven groups of the prediction errors of the model, and the average error is $19.7 \%$.

\section{Discussion}

6.1. Comparison of Two Models. The average error of the dimension analysis-based model is lower than that of the multi-nonlinear-regression model. More importantly, the dimension analysis-based model only needs to train one parameter, whereas the multi-nonlinear-regression model needs to train five. Besides, the multi-nonlinear-regression model comes purely from the data fitting while the dimension analysis-based model considers more physical meanings between the factors and model output. However, for both models, the size of the training data will limit the accuracy of prediction. In other words, the model prediction ability will be further improved by the use of more training data.

6.2. Sensitivity Analysis. A sensitivity analysis was conducted to identify which input parameters have the greatest effect on the model results and to understand the relative importance of the parameters for the predicted outcomes. The sensitivity values are based on the ratio of the change in the model outcome if the model input is varied [22]. We chose 30 groups of data as the database for the sensitivity analysis. These data are transformed into dimensionless numbers (between 0 and 1). Three of main factors remain constant at 0.5 while the other factor begins to increase from 0 to 1 . The results of both models are shown in Figure 10.

Obviously, the height/diameter ratio has greater sensitivity to compressive strength than the other factors. The friction effect of the end surface of the rock sample influences the compressive strength of rock, since the frictional effects produce a nonuniform distribution of the internal stress of the rock sample. When the height/diameter ratio of a rock sample is small, a three-dimensional stress state is more obvious within the rock, and therefore it has high strength; when the height/diameter ratio reaches $2: 1$, the internal stress distribution becomes quite even. At this moment, the height/diameter ratio of the rock does not affect the rock strength very much. Thus, the sensitivity of height/diameter ratio to compressive strength shows an increase first and then decreases. The degree of sensitivity to the compressive strength of shale of 


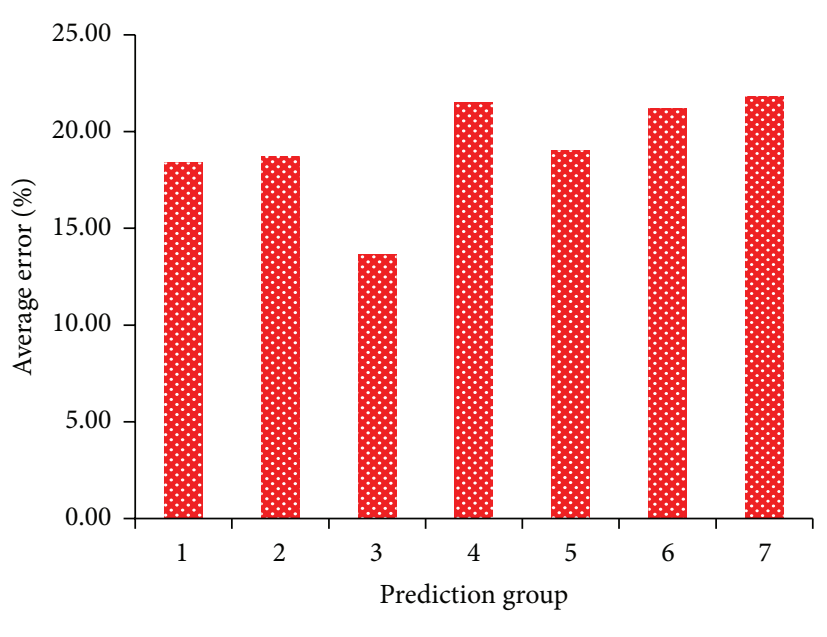

Model prediction

FIGURE 7: Prediction error of dimension analysis-based model.

the other parameters, namely, the porosity, bedding direction, and confining pressure, remains almost the same. The value of the rock porosity reflects the density of the rock. The greater the porosity of the rock, the lower the compressive strength. Not only does the effect of porosity on compressive strength reflect the size of porosity's impact, but more importantly, due to the directional distribution of the pores, the rock compressive strength shows anisotropy. To some extent, the pores lead to the anisotropic and heterogeneous distribution of shale bedding, resulting in different bedding directions in the shale. Interaction between porosity and anisotropic bedding may lower their sensitivity, respectively. Due to the increase of confining pressure, rock fissures are compacted, limiting the brittle damage of rock. Thus, the compressive strength of shale increases. However, a limited number of fractures would reduce the effect of the confining pressure on compressive strength. It is impossible to cause a substantial increase in compressive strength by increasing the confining pressure. As a result, there is a lower sensitivity to confining pressure.

6.3. Model Calculations of Peak Strength Coupled with Strain. In the case of compressive loading, the strong bonds between atoms are responsible for the high compressive strength of brittle materials. Material with higher brittleness tolerates a higher level of pressure without the occurrence of fracture $[23,24]$. On the other hand, ductile material accommodates more plastic deformation, and thus brittle material produces less deformation under compressive stress [25]. Thus,

$$
B \propto \frac{R}{\varepsilon_{p}},
$$

where $\varepsilon_{p}$ is the peak strain according to peak strength (stress). $B$ is proportional to brittleness.

Figure 11 shows the correlation between peak strength/ strain and the other factors (height/diameter ratio, porosity, bedding angle, and confining stress). Figure 12 demonstrates the prediction of the value of " $B$ " by the multi-nonlinearregression and dimension analysis models. It is found that there is still no large difference in prediction accuracy, although the dimension analysis model has a simpler structure than the nonlinear-regression model.

6.4. Limitations of Our Study. This study does not consider the disturbance loading in the project, such as dynamic and cyclic loads [26]. In addition, the method still needs a large number of test data to achieve better reliability. Finally, the model is mainly aimed at sedimentary rock such as shale and not at other rock types such as marble or granite.

\section{Conclusions}

Based on the compressive experiments on shale samples from Sichuan Basin, China, we developed a dimension analysis model for the prediction of shale peak strength. This model mainly considered the height/diameter ratio, porosity, confining stress, and bedding angle as the impact factors. Compared to the commonly used nonlinear-regression model, some valuable conclusions are as follows:

(1) The prediction ability of the dimension analysisbased model is not obviously different, but it has a much simpler structure than the multi-nonlinearregression model in the estimation of shale compressive strength.

(2) Multitraining and prediction can be used to increase and evaluate the reliability of modeling work.

(3) Height/diameter ratio has more sensitivity to compressive strength than other factors. The sensitivity of height/diameter ratio to compressive strength shows first an increase and then a decrease.

(4) With regard to the peak strength/strain (brittleness related), the prediction ability of both the nonlinearregression model and the dimension analysis-based model decreased. 


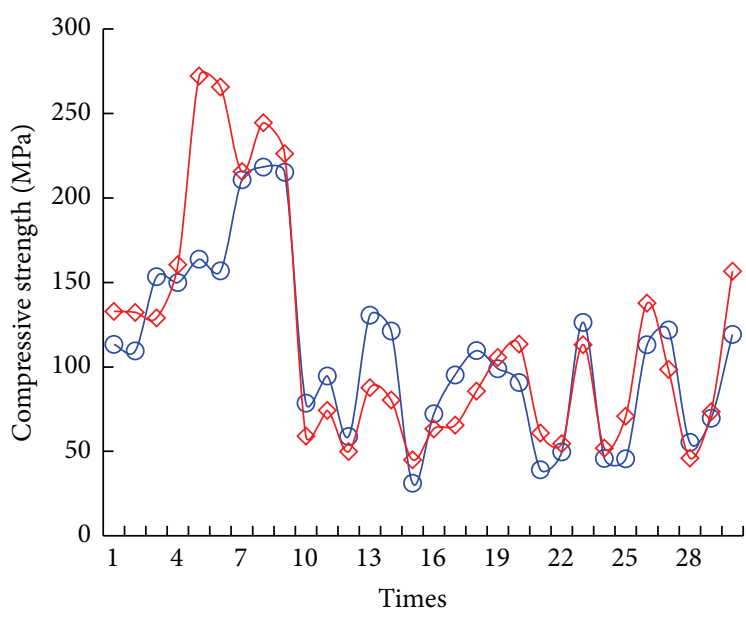

$\bigcirc$ Model fitting

$\diamond$ Real data

(a)

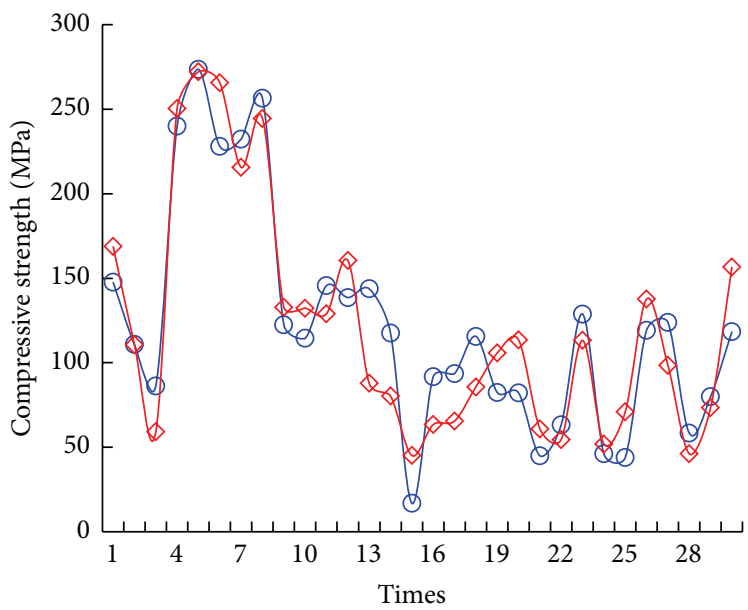

$\bigcirc$ Model fitting

$\diamond$ Real data

(c)

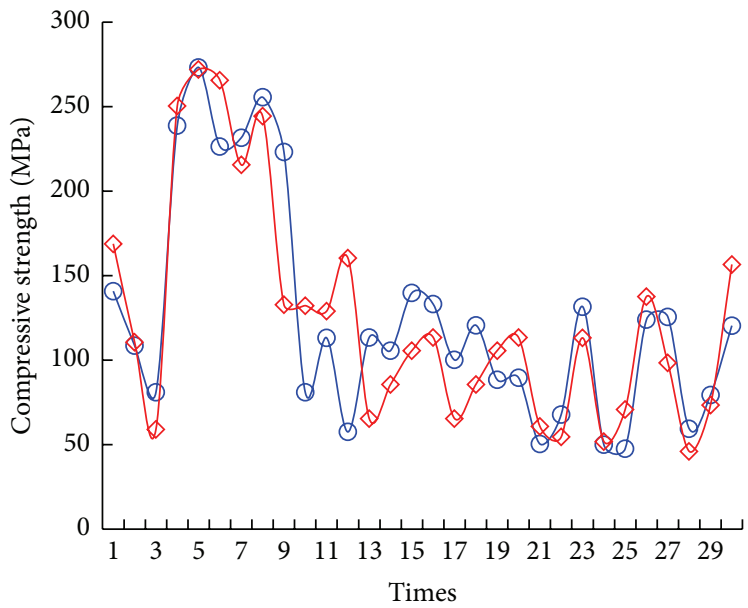

$\bigcirc$ Model fitting

$\diamond$ Real data

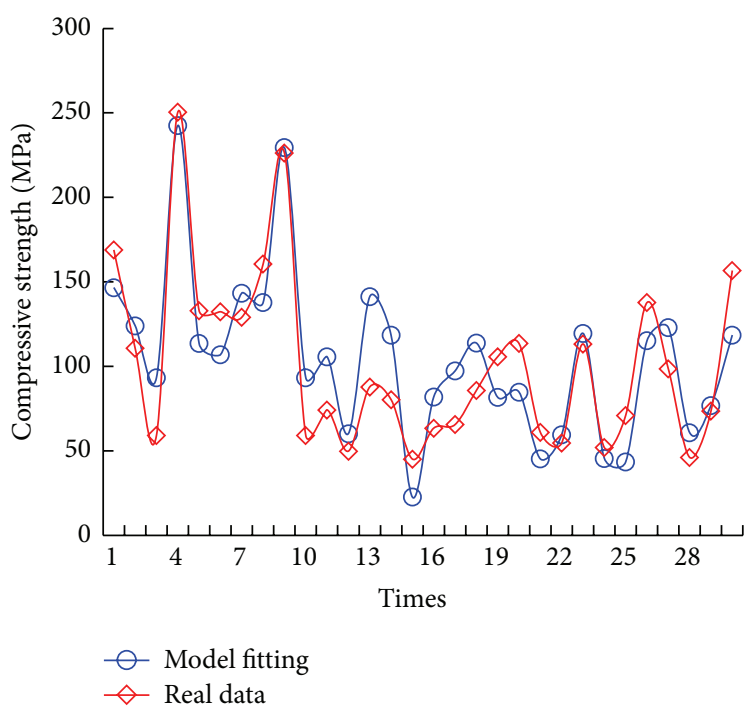

(b)

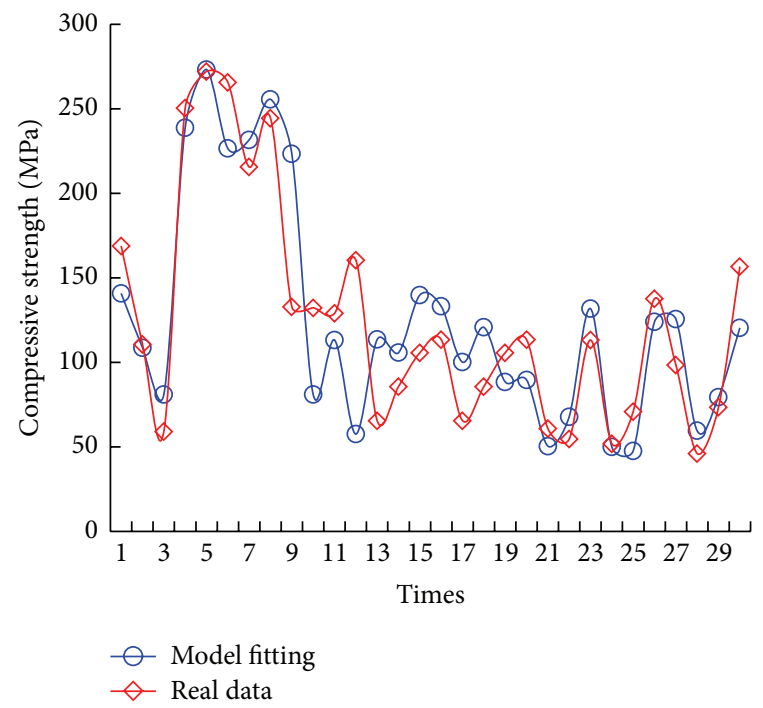

(d)

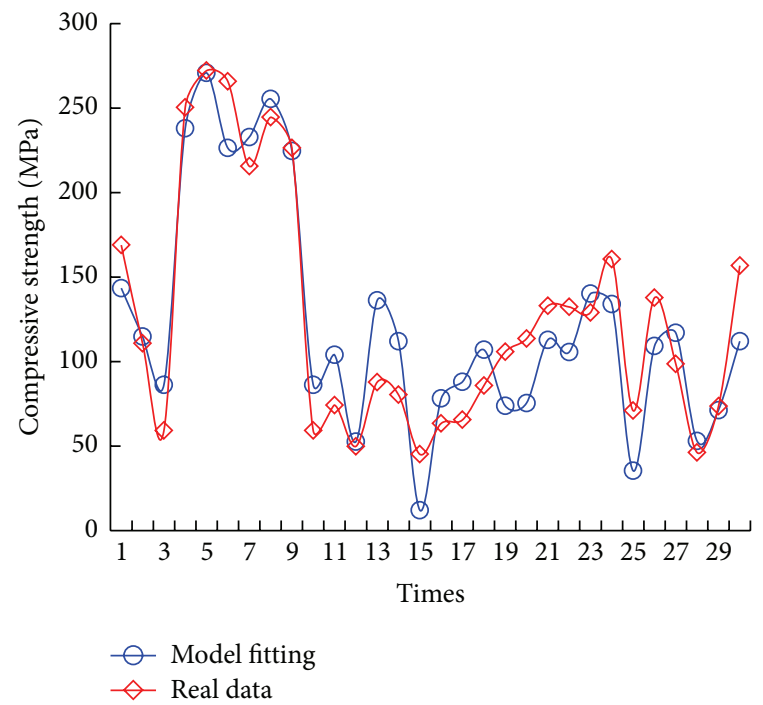

(f)

FIgure 8: Continued. 


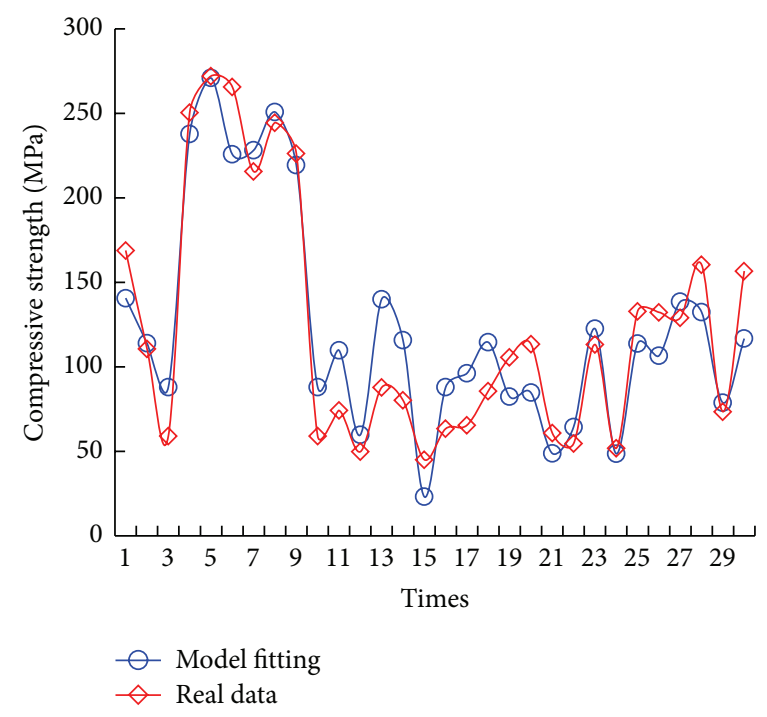

(g)

FIGURE 8: Multitraining results: (a) training on the first group of data; (b) training on the second group of data; (c) training on the third group of data; (d) training on the fourth group of data; (e) training on the fifth group of data; (f) training on the sixth group of data; (g) training on the seventh group of data.

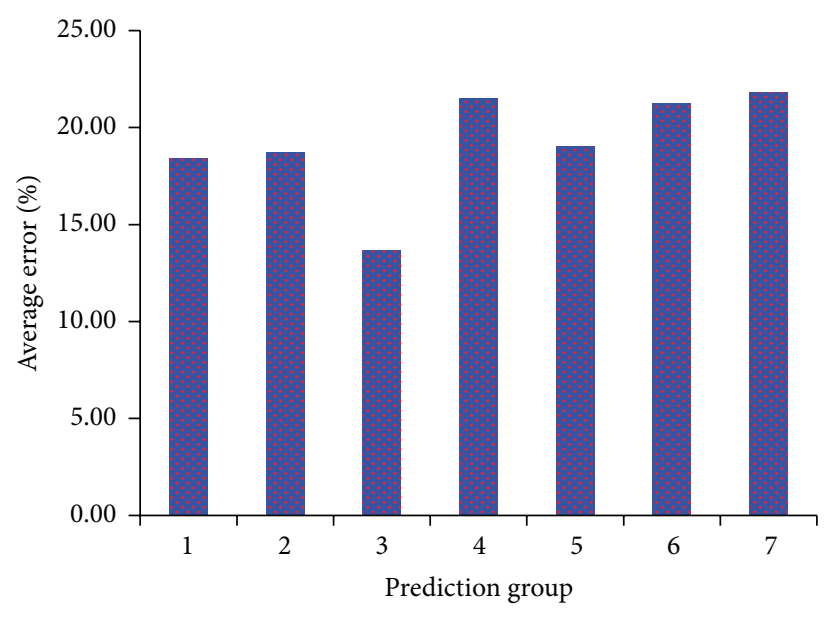

- Model prediction

FIGURE 9: Prediction error of multi-nonlinear-regression model.

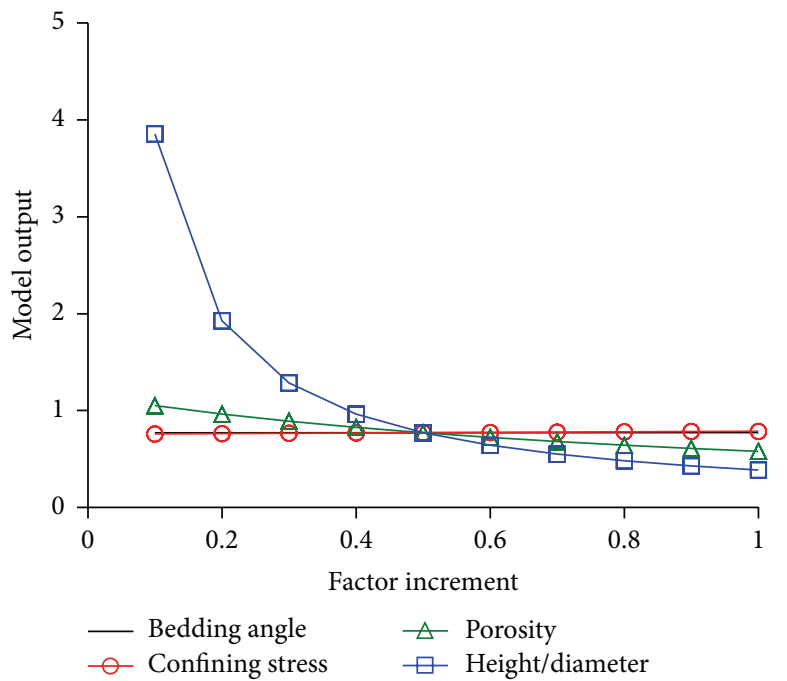

(a)

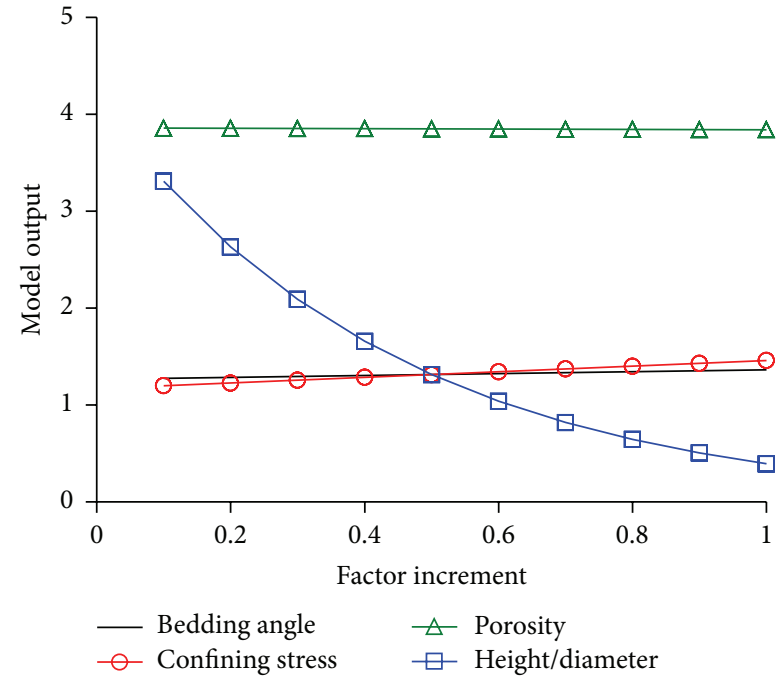

(b)

FIGURE 10: Sensitivity analysis of both models: (a) dimension analysis-based model; (b) multi-nonlinear-regression model. 


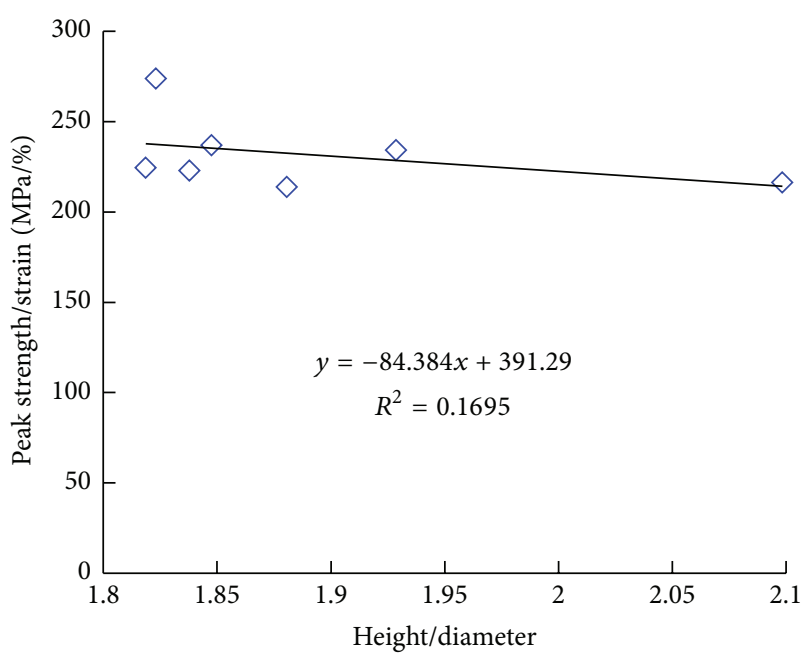

(a)

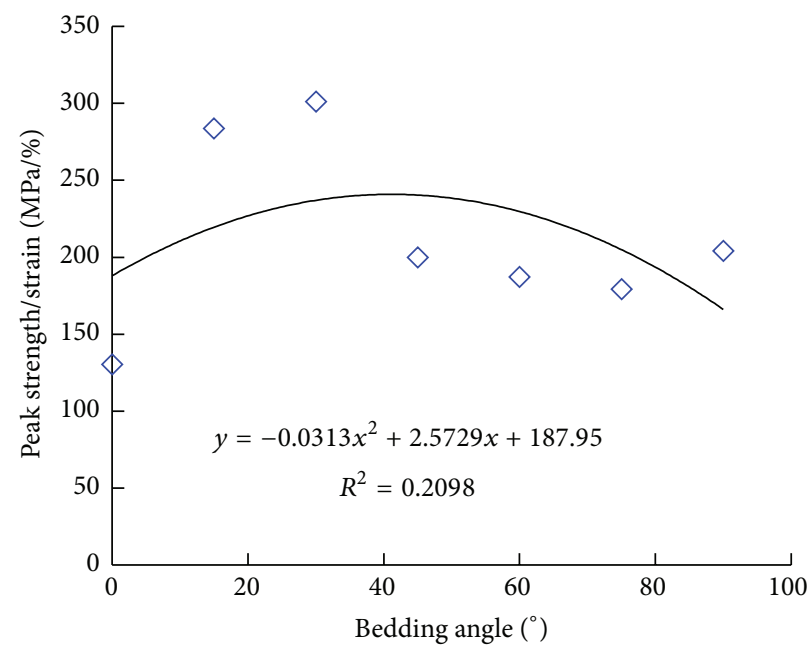

(c)

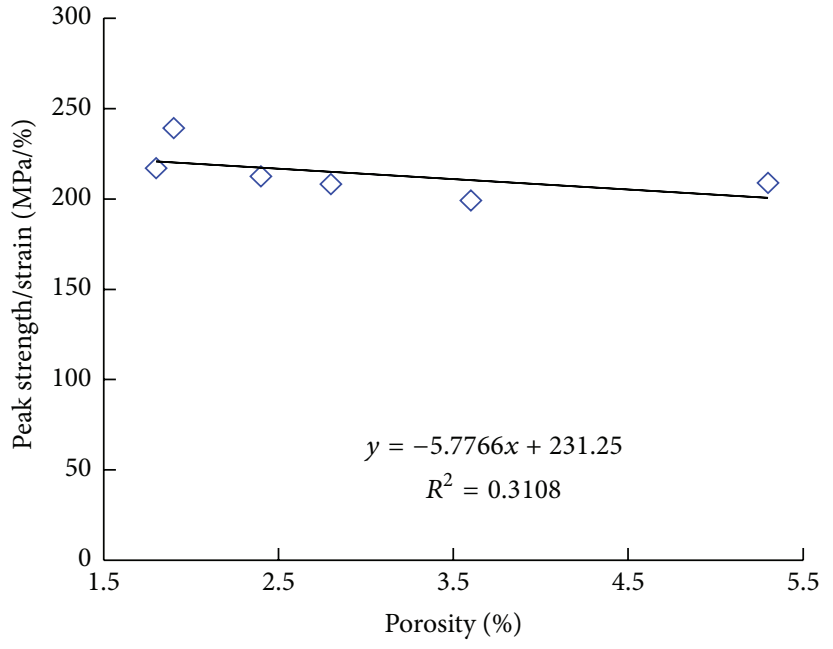

(b)

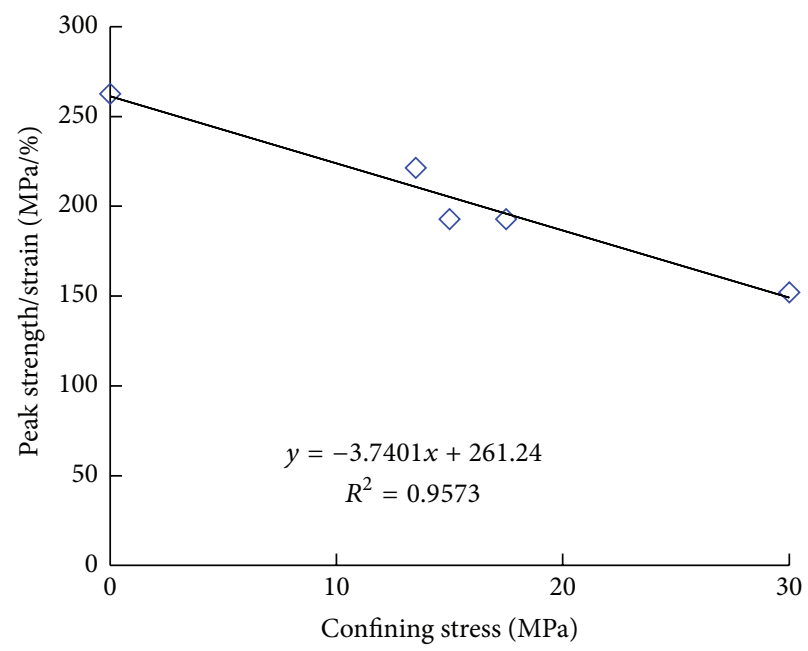

(d)

FIGURE 11: Correlation analysis: (a) height/diameter ratio versus peak strength/strain; (b) porosity versus peak strength/strain; (c) confining stress versus peak strength/strain; $(\mathrm{d})$ bedding angle versus peak strength/strain.

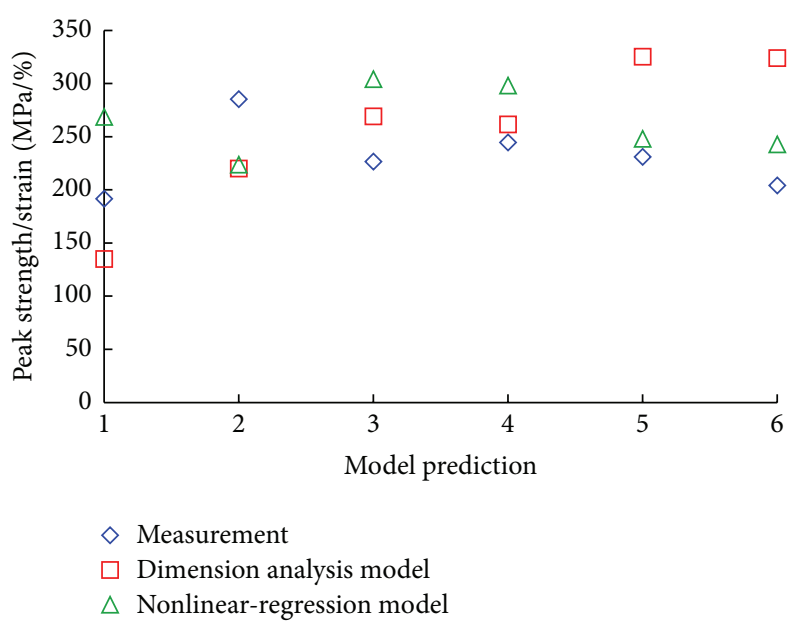

FIGURE 12: Predictions of multi-nonlinear-regression and dimension analysis models (using the data in Figure 8(a) for training and the rest of the data for validation; the relative average error of the dimension analysis model is $22.04 \%$ and the relative average error of the multinonlinear-regression model is $21.89 \%$ ). 


\section{Competing Interests}

The authors declare that they have no competing interests.

\section{Acknowledgments}

The research is supported by the Open Fund (PLN1502) of the State Key Laboratory of the Oil and Gas Reservoir Geology and Exploitation, Southwest Petroleum University, Chongqing Land Bureau Science and Technology Planning Project (Grant no. CQGT-KJ-2014017), the National Natural Science Foundation of China (Grant no. 51474185), the National Key Basic Research Program of China (973 Program), and the Shale Gas Horizontal Well Drilling and Completion Key Basic Research (Grant no. 2013CB228003).

\section{References}

[1] A. J. L. Crook, J. G. Yu, and S. M. Willson, "Development of an orthotropic 3D elastoplastic material model for shale," in Proceedings of the SPE/ISRM Rock Mechanics Conference, San Antonio, Tex, USA, October 2002.

[2] O. K. Søreide, B. Bostrøm, and P. Horsrud, "Borehole stability simulations of an HPHT field using anisotropic shale modeling," in Proceedings of the ARMA Conference, vol. 1 of ARMA09-185, Asheville, NC, USA, July 2008.

[3] M. A. Islam and P. Skalle, "An experimental investigation of shale mechanical properties through drained and undrained test mechanisms," Rock Mechanics and Rock Engineering, vol. 46, no. 6, pp. 1391-1413, 2013.

[4] Q. Lyu, P. G. Ranjith, X. Long, Y. Kang, and M. Huang, "Effects of coring directions on the mechanical properties of Chinese shale," Arabian Journal of Geosciences, vol. 8, no. 12, pp. 1028910299, 2015.

[5] J. A. Hudson, S. L. Crouch, and C. Fairhurst, "Soft, stiff and servo-controlled testing machines: a review with reference to rock failure," Engineering Geology, vol. 6, no. 3, pp. 155-189, 1972.

[6] E. Hoek, "Rock engineering course notes by Evert Hoek," 2000, http://www.rocscience.com/education/hoeks_corner.

[7] P. J. N. Pells, "On the absence of size effects for substance strength of Hawkesbury Sandstone," Australian Geomechanics, vol. 39, pp. 79-83, 2004.

[8] W. J. Darlington, P. G. Ranjith, and S. K. Choi, "The effect of specimen size on strength and other properties in laboratory testing of rock and rock-like cementitious brittle materials," Rock Mechanics and Rock Engineering, vol. 44, no. 5, pp. 513529, 2011.

[9] L. Li and M. Aubertin, "A general relationship between porosity and uniaxial strength of engineering materials," Canadian Journal of Civil Engineering, vol. 30, no. 4, pp. 644-658, 2003.

[10] C. Chang, M. D. Zoback, and A. Khaksar, "Empirical relations between rock strength and physical properties in sedimentary rocks," Journal of Petroleum Science and Engineering, vol. 51, no. 3-4, pp. 223-237, 2006.

[11] P. Horsrud, "Estimating mechanical properties of shale from empirical correlations," SPE Drilling \& Completion, vol. 16, no. 2, pp. 68-73, 2001.

[12] G. R. Lashkaripour and M. B. Dusseault, "A statistical study on shale properties: relationship among principal shale properties," in Proceedings of the Conference on Probabilistic Methods in
Geotechnical Engineering, pp. 195-200, Canberra, Australia, February 1993.

[13] W. G. Liang, C. H. Yang, Y. S. Zhao, M. B. Dusseault, and J. Liu, "Experimental investigation of mechanical properties of bedded salt rock," International Journal of Rock Mechanics and Mining Sciences, vol. 44, no. 3, pp. 400-411, 2007.

[14] M. Lal, "Shale stability: drilling fluid interaction and shale strength," in Proceedings of the SPE 6th Latin American and Caribbean Petroleum Engineering Conference, pp. 1-10, Society of Petroleum Engineers, April 1999.

[15] F. S. Jeng, M. C. Weng, M. L. Lin, and T. H. Huang, "Influence of petrographic parameters on geotechnical properties of tertiary sandstones from Taiwan," Engineering Geology, vol. 73, no. 1-2, pp. 71-91, 2004.

[16] K. Zorlu, C. Gokceoglu, F. Ocakoglu, H. A. Nefeslioglu, and S. Acikalin, "Prediction of uniaxial compressive strength of sandstones using petrography-based models," Engineering Geology, vol. 96, no. 3-4, pp. 141-158, 2008.

[17] J. B. Curtis, "Fractured shale-gas systems," AAPG Bulletin, vol. 86, no. 11, pp. 1921-1938, 2002.

[18] K. A. Bowker, "Barnett Shale gas production, Fort Worth Basin: issues and discussion," AAPG Bulletin, vol. 91, no. 4, pp. 523533, 2007.

[19] D. J. K. Ross and R. M. Bustin, "The importance of shale composition and pore structure upon gas storage potential of shale gas reservoirs," Marine and Petroleum Geology, vol. 26, no. 6, pp. 916-927, 2009.

[20] R. M. Pollastro, D. M. Jarvie, R. J. Hill, and C. W. Adams, "Geologic framework of the Mississippian Barnett Shale, BarnettPaleozoic total petroleum system, Bend arch-Fort Worth Basin, Texas," AAPG Bulletin, vol. 91, no. 4, pp. 405-436, 2007.

[21] B. Kent, "Recent development of the Barnett Shale Play, Fort Worth Basin," West Texas Geological Society Bulletin, vol. 2, article 9, p. 6, 2003.

[22] D. M. Hamby, Environmental Monitoring and Assessment, Kluwer Academic, Dordrecht, The Netherlands, 1994.

[23] W. F. Wu, Y. Li, and C. A. Schuh, "Strength, plasticity and brittleness of bulk metallic glasses under compression: statistical and geometric effects," Philosophical Magazine, vol. 88, no. 1, pp. 7189, 2008.

[24] L. Graham-Brady, "Statistical characterization of meso-scale uniaxial compressive strength in brittle materials with randomly occurring flaws," International Journal of Solids and Structures, vol. 47, no. 18-19, pp. 2398-2413, 2010.

[25] M. S. Paterson and T. F. Wong, Experimental Rock Deformation-The Brittle Field, Springer Science \& Business Media, 2005.

[26] A. Taheri, A. Royle, Z. Yang, and Y. Zhao, "Study on variations of peak strength of a sandstone during cyclic loading," Geomechanics and Geophysics for Geo-Energy and Geo-Resources, vol. 2, no. 1, pp. 1-10, 2016. 

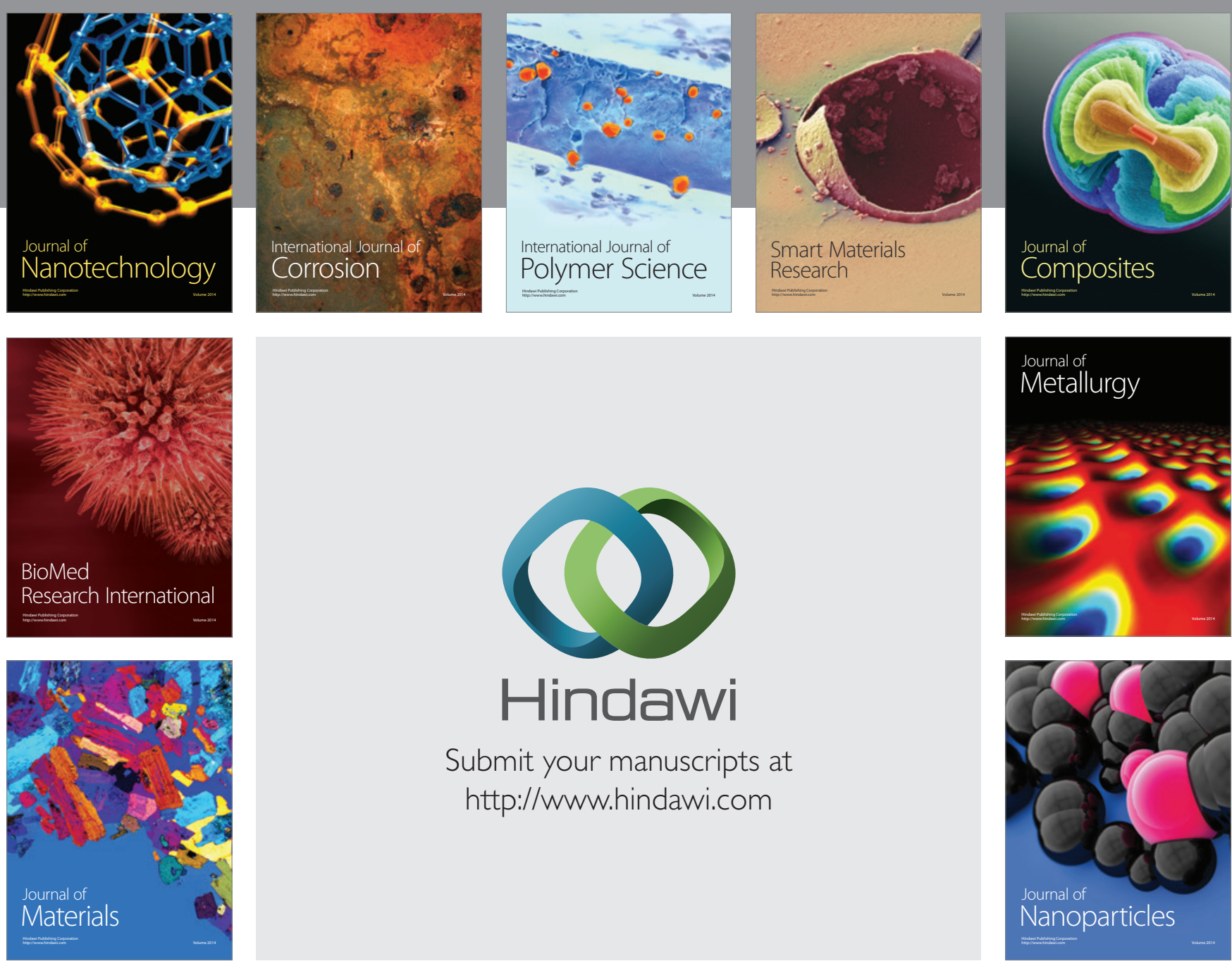

\section{Hindawi}

Submit your manuscripts at

http://www.hindawi.com

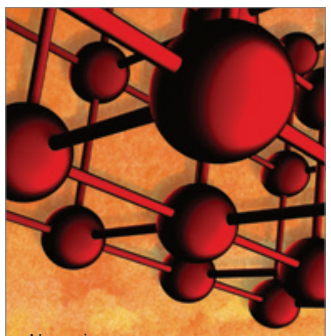

Materials Science and Engineering
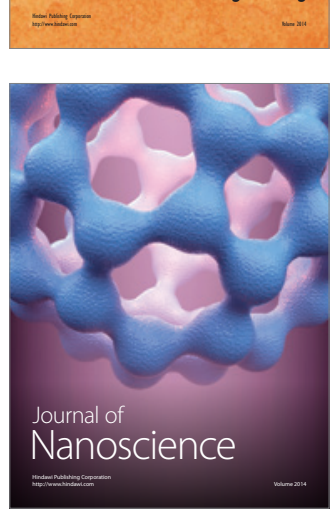
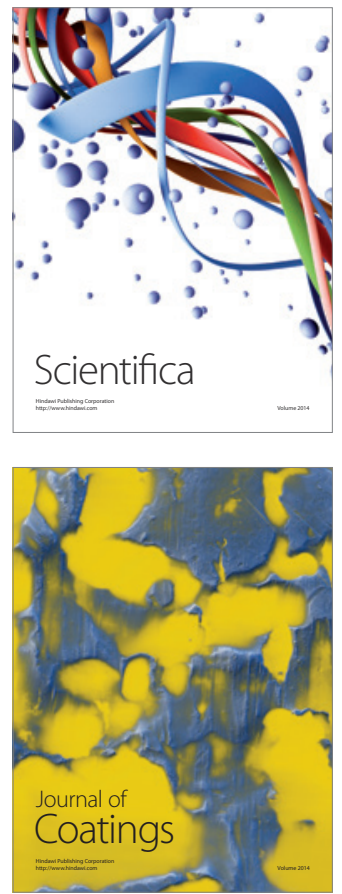
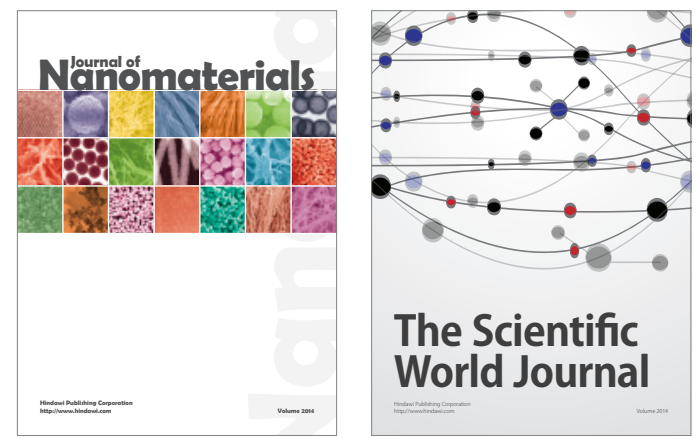

The Scientific World Journal
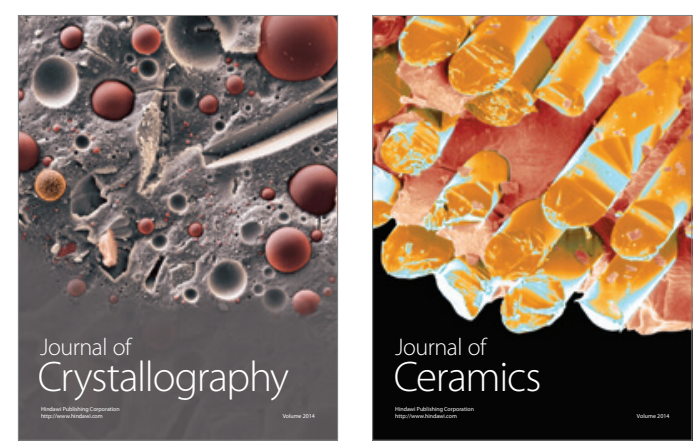
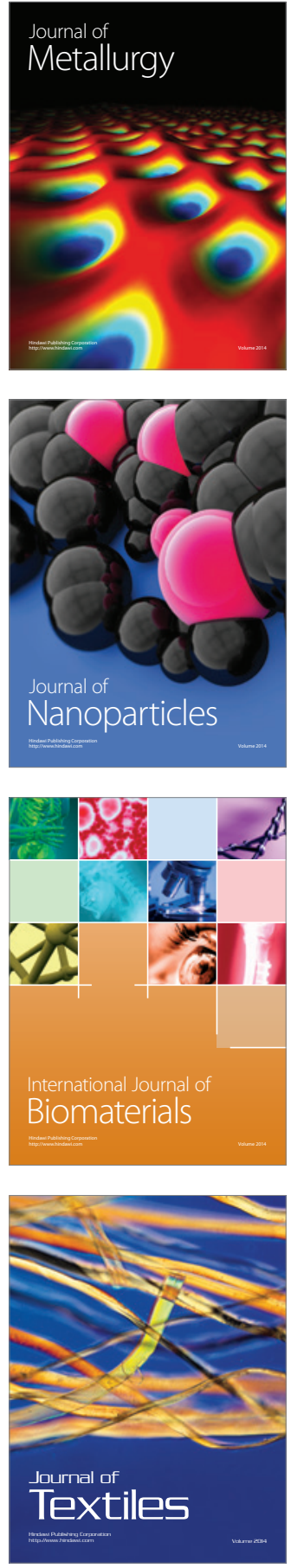